\title{
MỘT SỐ BIỆN PHÁP TẠO HÚNG THÚ HỌC TẬP CHO HỌC SINH \\ ĐỂ NÂNG CAO HIỆU QUẢ DẠY HỌC Ở TIỂU HỌC
}

\section{Some solutions creating student's interest in order to improve teaching effectiveness at primary education}

\author{
GS.TS. Lê Phương Nga* \\ PGS.TS. Trần Ngọc Lan*
}

\section{TÓM TẮT}

Hưng thú là một thuộc tính tâm lí - nhân cách quan trọng của con người. Cùng với tụ giác, hứng thú làm nên tính tích cưc nhận thức, giúp học sinh học tập đạt kết quả cao, có khả năng khơi dậy mạch nguồn của sụ sáng tạo. Hứng thú không tư nhiên nảy sinh và khi đã nảy sinh nếu không duy trì, nuôi duỡng cũng có thể bị mất đi. Hứng thú được hình thành, duy trì và phát triển nhò̀ môi trương giáo dục với vai trò dẫn dắt, hướng dẫn, tổ chức của giáo viên. Giáo viên là người có vai trò quyết định trong việc phát hiện, hình thành, bồi dương hưng thú học tập cho hoc sinh. Bài viết này chura đặt ra vấn đề bàn lại muc tiêu và chuoong trình của tùng môn học. Đó là một vấn đề lớn của một công trình nghiên cưu khác. Ở đây chúng tôi chỉ bàn đến nhũng biện pháp tạo hứng thú học tập trên một chuơng trình dạy học đang được thưc thi.Vì vây, thành tố muc tiêu chỉ giới hạn ở làm cho học sinh nhận thức muc tiêu, lợi ích của bài học. Cũng do khuôn khổ của bài viết, trong phần trình bày nhóm biện pháp tác động vào nội dung dạy hoc, chỉ tập trung minh họa ở môn Tiếng Việt và trong phần trình bày nhóm biện pháp tác động vào phưong pháp dạy học, chỉ tập trung lấy dẫn chứng ở môn Toán. Nhũng luận điểm và ý tưởng tạo hứng thú học tập cho hoc sinh tiểu học được đề cập ở đây không chỉ nhằm áp dụng cho hai môn học này.

Tù̀ khoá: hứng thú, học tập, học sinh

\begin{abstract}
Interest is an important aspect of human regarding psychology and personality. Parallel with self-consciousness, interest create positive cognitiveness and may help students achieve high learning performances and being able to recall sources of creativity. Interest is not naturally created, and even if it is created but not be well maintained, it may disappear. Interest is formed, maintained and developed based on educational environment with the role of guidance and organisation of teachers. Teachers have decessive roles in discovering, forming and and nurturing students' interest. This paper does not discuss about aims and curriculem of each subject, as it is a big issue belonging to a bigger study. The author only present solutions creating learning interest based on a current teaching approach. Therefore, in a narrower scope, it limits on helping students to realise purpose and benefit of the subject. In this paper, in the section of solutions affecting teaching content, it only focuses on illustrations in Vietnamese subject, and in the section of solutions affecting teaching approach, it focuses on presenting examples of Mathematic subject. Ideas and assumptions of creating primary student's interest which are mentioned in this paper, only aim to apply for those two subjects.
\end{abstract}

Keywords: interest; learning, students. 
Hứng thú là một thuộc tính tâm lí - nhân cách quan trọng của con người. Hứng thú có vai trò rất quan trọng trong học tập và làm việc, không có việc gì người ta không làm được dưới ảnh hưởng của hứng thú. M. Gorki từng nói “Thiên tài nảy nở từ tình yêu đối với công việc". Cùng với tự giác, hứng thú làm nên tính tích cực nhận thức, giúp học sinh (HS) học tập đạt kết quả cao, có khả năng khơi dậy mạch nguồn của sự sáng tạo. Trong khi đó, việc khảo sát thực tế dạy học ở tiểu học bằng nhiều con đường (lấy phiếu hỏi từ các cấp quản lí giáo dục; từ các giáo viên $(\mathrm{GV})$, các bậc phụ huynh và $\mathrm{HS}$, quan sát và làm các đo nghiệm khách quan trên $\mathrm{HS}$ ) đã cho thấy nhiều HS tiểu học không có hứng thú trong học tập. Điều này vừa được xem như là một biểu hiện vừa được xem như là một nguyên nhân rất quan trọng của việc suy giảm chất lượng dạy học ở tiểu học.

Những biện pháp tạo hứng thú trong bài viết này xuất phát từ 3 luận điểm cơ bản: Một là "Hiệu quả thưc sục của việc dạy hoc là hoc sinh biết tụ hoc; tụ hoàn thiện kiến thức và tụ rèn luyện kỹ năng", hai là "Nhiệm vu khó khăn và quan trọng nhất của giáo viên là làm sao cho học sinh thích học", ba là: "Dạy học ở tiểu học là phải làm cho học sinh cảm thấy biết thêm kiến thức của mỗi bài học ở mối môn học là có thêm nhũng điều bổ ích, lý thú tù một góc nhìn cuộc sống”.

Với ba luận điểm này, chúng tôi quan niệm rằng thực chất của việc dạy học là truyền cảm hứng và đánh thức khả năng tự học của người học. Còn nếu quan niệm là người dạy truyền thụ, người học tiếp nhận thì người dạy dù có hứng thú và nỗ lực đến mấy mà chưa truyền được cảm hứng cho HS, chưa làm cho người học không thấy cái hay, cái thú vị, giá trị chân thực mà tri thức đem lại thì giờ dạy vẫn không có hiệu quả. Người học chỉ tự giác, tích cực học tập khi họ thấy hứng thú. Hứng thú không có tính tự thân, không phải là thiên bẩm. Hứng thú không tự nhiên nảy sinh và khi đã nảy sinh nếu không duy trì, nuôi dưỡng cũng có thể bị mất đi. Hứng thú được hình thành, duy trì và phát triển nhờ môi trường giáo dục với vai trò dẫn dắt, hướng dẫn, tổ chức của $G V$. $G V$ là người có vai trò quyết định trong việc phát hiện, hình thành, bồi dưỡng hứng thú học tập cho HS.

Quá trình dạy học gồm 5 thành tố cơ bản: Mục đích dạy học, nội dung dạy học, phương pháp và hình thức tổ chức dạy học, phương tiện và thiết bị dạy học, kiểm tra đánh giá kết quả học tập.

Với các thành tố đó, có nhiều nhóm biện pháp tạo hứng thú học tập cho HS và chúng thuộc những bình diện khác nhau của quá trình dạy học. Có biện pháp tác động vào việc trình bày mục tiêu bài học, có biện pháp tác động vào nội dung dạy học, có biện pháp tác động vào phương pháp, hình thức tổ chức dạy học, có biện pháp tác động vào phương tiện, thiết bị dạy học, có biện pháp tác động vào kiểm tra đánh giá (bao gồm cả nhận xét), tác động vào quan hệ tương tác thân thiện giữa thầy - trò, trò - trò...

Bài viết này chưa đặt ra vấn đề bàn lại mục tiêu và chương trình của từng môn học. Đó là một vấn đề lớn của một công trình nghiên cứu khác. Ở đây chúng tôi chỉ bàn đến những biện pháp tạo hứng thú học tập trên một chương trình dạy học đang được thực thi. Vì vậy, thành tố mục tiêu chỉ giới hạn ở làm cho HS nhận thức mục tiêu, lợi ích của bài học. Cũng do khuôn khổ của bài viết, trong phần trình bày nhóm biện pháp tác động vào nội dung dạy học, chỉ tập trung minh họa ở môn Tiếng Việt và trong phần trình bày nhóm biện pháp tác động vào phương pháp dạy học, chỉ tập trung lấy dẫn chứng ở môn Toán. Những luận điểm và ý tưởng tạo hứng thú học tập cho HS tiểu học được đề cập ở đây không chỉ nhằm áp dụng cho hai môn học này. 


\section{Tạo hứng thú học tập bằng cách làm cho học sinh nhận thức được mục tiêu, lợi ích} của bài học

Hứng thú là một thuộc tính tâm lí mang tính đặc thù cá nhân. Hứng thú có tính lựa chọn. Đối tượng của hứng thú chỉ là nhũng cái cần thiết, có giá trị, có sức hấp dẫn với cá nhân. Vậy vấn đề gì thu hút sự quan tâm, chú ý tìm hiểu của các em? Trả lời được câu hỏi này tức là người $\mathrm{GV}$ đã sống cùng với đời sống tinh thần của các em, biến đổi những nhiệm vụ học tập khô khan phù hợp với những mong muốn, nhu cầu, sở thích, nguyện vọng (tất nhiên là phải tích cực, chính đáng) của HS.

Hứng thú học tập trước hết được tạo ra bằng cách làm cho HS ý thức được lợi ích của việc học để tạo động cơ học tập. Mục tiêu này có thể được trình bày một cách tường minh ngay trong tài liệu học tập (như cách trình bày của tài liệu hướng dẫn học của dự án Mô hình trường học mới Việt Nam) hoặc có thể trình bày thông qua các tình huống dạy học cụ thể.

Ngay từ những ngày đầu HS đến trường, chúng ta cần làm cho các em nhận thức về lợi ích của việc học một cách tích cực và thiết thực "Con mà biết chữ thì thật là thú vị. Cô có thể viết cho con lời nhắn, con có thể đọc truyện...", "Con làm được một đồ chơi đẹp, vẽ được một bức tranh đẹp, làm thế nào để mẹ và cô biết là của con. Hãy học để viết tên lên đồ chơi và tranh nhé!", "Và đây là căn nhà đầy đồ chơi. Chìa khóa để mở có ghi một chữ, ai biết đọc sẽ mở được ngay", "Đây là một vương quốc thật diệu kì chỉ dành cho những người biết đọc, biết viết"...

Với mỗi bài học cụ thể, GV cần giúp cho HS nhận ra tính lợi ích của một nội dung nào đó. Chẳng hạn, sự cần thiết của dấu phẩy sẽ được làm rõ khi chỉ ra sự khác nhau về nghĩa của hai câu: "Đêm hôm, qua cầu gãy" và " Đêm hôm qua, cầu gãy". Tính lợi ích của một nội dung dạy học cũng được thể hiện rõ khi chúng ta đặt ra sự đối lập giữa "có nó" và "không có nó", ví dụ: Điều gì sẽ xảy ra khi chúng ta không có chữ viết? Chuyện gì sẽ xảy ra khi chúng ta không có những từ đồng nghĩa, không có câu ghép?...

\section{Tạo hứng thú học tập bằng cách tác động vào nội dung dạy học}

Nội dung dạy học được chia ra rất nhiều cấp độ. Ví dụ như trong môn Tiếng Việt, trước hết đó là các phân môn, các mạch kiến thức - kĩ năng, cụ thể hóa đến nhóm, kiểu, dạng bài tập và cho đến tận từng bài tập cụ thể. Từ bình diện nội dung dạy học, trên một bài tập, ta có thể tác động vào phần lệnh hoặc phần ngữ liệu.

Việc trình bày đầy đủ các biện pháp tạo hứng thú trên bình diện nội dung dạy học cần cả một quyển sách. Sau đây chúng tôi chỉ lấy một vài dẫn chứng về việc lựa chọn ngữ liệu dạy học tiếng Việt.

Không có con đường nào khác để làm nảy sinh và duy trì hứng thú của HS với tiếng Việt và văn học ngoài cách giúp các em thấy được sự thú vị, vẻ đẹp và khả năng kì diệu của chính đối tượng học tập - Tiếng Việt, văn chương. Đây cũng chính là ngữ liệu của dạy tiếng.

Từng giờ, từng phút trong giờ tiếng Việt, người $\mathrm{GV}$ đều hướng đến hình thành và duy trì hứng thú cho HS. Đó có thể là một lời vào bài hấp dẫn cho giờ tập đọc: "Đây là một con chim sẻ rất nhỏ bé. Thế nhưng nhà văn Tuốc-ghê-nhép đã kính cẩn nghiêng mình thán phục trước nó, vì sao vậy? Chúng ta hãy cùng nhau đọc bài Con sẻ để trả lời câu hỏi này”. Hứng thú của HS cũng được 
khơi dậy từ việc chỉ ra vẻ đẹp của một từ, cái hay của một tình tiết truyện, chẳng hạn: Tiếng hót của chim chiền chiện không phải "ríu rít", "thánh thót" mà "ngọt ngào", "long lanh", "chan chứa" thì mới gây ấn tượng. Hoa sầu riêng nở "tím ngát" chứ không phải chỉ "tím ngắt" hay "ngan ngát". Như thế thì mới có cả màu hoa, hương hoa chỉ trong một từ. Tình tiết người mẹ cho hồ nước đôi mắt của mình để tìm đường đến chỗ Thần Chết đòi trả lại con trong chuyện Người mẹ của An-đéc-xen đến nay còn lay động tâm can biết bao người...

Ngay cả những vấn đề lí thuyết ngữ pháp khô khan cũng đều có thể gây hứng thú cho HS nếu chúng ta biết lựa chọn ngữ liệu khai thác những đặc điểm thú vị của tiếng Việt, chẳng hạn đó là mối quan hệ giữa kiểu nghĩa và cấu tạo từ, giá trị gợi tả gợi cảm của lớp từ láy, quy luật chuyển nghĩa của từ nhiều nghĩa; khả năng tạo những "định danh nghệ thuật", "đồng nghĩa kép" của hiện tượng đồng nghĩa, sự bất ngờ thú vị của hiện tượng đồng âm. Chẳng hạn, bài tập phân tích nghĩa của câu sẽ thú vị nếu GV sử dụng ngữ liệu đồng âm, đặc biệt là đồng âm cú pháp. Ví dụ: "Nhiều bạn gái đang múa hát rất hay, chúng tôi học qua loa” .

Ngữ liệu tiếng Việt trở nên hấp dẫn khi thể hiện tính năng sản của ngôn ngữ. Ví dụ, tiếng hoc, từ tay... hoàn toàn trở thành ngữ liệu hấp dẫn trong các bài tập: "Tìm các từ có chung tiếng tiếng $h o c$ ", "Tìm thành ngữ, tục ngữ cùng chứa từ tay"... Vì tiếng hoc có mặt trong rất nhiều từ ngữ: hoc bạ, học bổng, hoc cu, học đòi, học đường, học gạo, học giả, hoc hành, học hỏi, học kì, học lóm, học phí, hoc sinh, hoc tập...; từ tay xuất hiện trong 21 thành ngữ, tục ngữ.

Ngữ liệu hấp dẫn phản ánh được nét độc đáo của tiếng Việt, một ngôn ngữ đơn lập mà phương thức ngữ pháp chủ yếu là trật tự từ. Với bài tập yêu cầu HS sắp xếp các từ cho trước để tạo câu, nên chọn những từ có khả năng sắp xếp thành nhiều câu khác nhau, ví dụ nếu chọn 5 từ sao, nó, không, đến, bảo có khả năng tạo thành trên 50 câu khác nhau.

Những kiến thức ngữ pháp nên được xem xét dưới góc độ của người sử dụng ngôn ngữ sẽ gây được hứng thú. Ví dụ, dạy bài "Danh từ riêng” có thể bắt đầu bằng cách nhận xét về cách đặt tên của người Việt. Khi dạy "Đại từ nhân xưng”, có thể cho HS nhận xét về văn hoá của người Việt trong cách xưng hô. HS chưa hiểu hết được sự tế nhị trong cách xưng hô của người Việt và không phải em nào cũng biết xưng hô với bạn bè, cha mẹ, người thân một cách có văn hoá nên phát hiện này đối với các em cũng là điều thú vị...

Không có cách gì tạo ra hứng thú với tiếng mẹ đẻ và văn chương ngoài con đường cho trẻ tiếp xúc trực tiếp, càng nhiều càng tốt với những tác phẩm văn chương, những mẫu hình sử dụng ngôn ngữ mẫu mực vì "Không làm thân với văn thơ thì không nghe thấy được tiếng lòng chân thật của nó”. (Lê Trí Viễn).

\section{Tạo hứng thú học tập bằng cách sứ dụng linh hoạt các phương pháp và hình thức tổ} chức dạy học

Ngoài việc khai thác sự lí thú trong chính nội dung dạy học, hứng thú của HS còn được hình thành và phát triển nhờ các phương pháp, thủ pháp, hình thức tổ chức dạy học phù hợp với sở thích của các em. Đó chính là cách tổ chức dạy học dưới dạng các trò thi đố, các trò chơi,tổ chức hoạt 
động sắm vai, tổ chức hoạt động học theo nhóm, tổ chức dạy học dự án, tổ chức dạy học ngoài không gian lớp học...

\section{Tổ chức trò chơi học tập:}

Trong thực tế dạy học, giờ học nào tổ chức trò chơi cũng đều gây được không khí học tập hào hứng, thoải mái, vui nhộn. Nghiên cứu cho thấy, trò chơi học tập có khả năng kích thích hứng thú và trí tưởng tượng của trẻ em, kích thích sự phát triển trí tuệ của các em.

Trò chơi học tập nhất thiết phải là một bộ phận của nội dung bài học, phải là một phần cấu tạo nên bài học. Trong trò chơi, khi mọi thứ đều thật, chẳng hạn trong môn Tiếng Việt, từ vẫn là từ, câu vẫn là câu, trò vẫn là trò, thầy vẫn là thầy..., trò chơi sẽ bớt phần thú vị. Trò chơi cuốn hút trẻ em hơn nếu có được sự giả định từ tên gọi, từ người tham gia, từ tình huống đến kết quả chơi. Ví dụ nhóm trò chơi Trong vườn cổ tích đã khai thác tính giả định của trò chơi từ nguồn văn bản truyện cổ. Khi đó, trò chơi vừa minh hoạ sinh động kiến thức, kĩ năng tiếng Việt, vừa tạo ra được một không khí cổ tích huyền diệu, gợi lại nội dung các văn bản truyện cổ mà HS đã học ở phân môn Tập đọc hay Kể chuyện. Ví dụ, từ truyện Tấm Cám, xây dựng trò chơi "Chim sẻ giúp cô Tấm” dành cho các bài tập nhận diện, phân loại,... Từ truyện Sơn Tinh Thuỷ Tinh, có thể xây dựng trò chơi "Dâng núi chống lụt" cho những bài tập chính tả, làm giàu vốn từ,...

Có thể kể đến trò chơi học tập hoạt động sắm vai. Đây là một trò chơi có rất nhiều lợi thế để dạy học Tiếng Việt. Sắm vai trong dạy học là nhận một vai giao tiếp nào đó nhằm thể hiện sinh động nội dung học tập. Hình thức học tập sắm vai nhiều khi rất vui nhờ những chi tiết hài hước, ngộ nghĩnh do những "diễn viên bất đắc dî” tạo nên. Hình thức sắm vai đặc biệt phát huy tác dụng trong các giờ tập làm văn rèn kĩ năng nói, nó giúp HS được thực hành giao tiếp, được quan sát trực tiếp hoạt động nói với sự kết hợp sinh động của phương tiện âm thanh và các yếu tố phi ngôn ngũ̃.

\section{Tổ chức hoạt động học theo nhóm}

Học theo nhóm là hình thức học tập có sự hợp tác của nhiều thành viên trong lớp nhằm giải quyết những nhiệm vụ học tập chung. Được tổ chức một cách khoa học, học theo nhóm sẽ phát huy tính tích cực, sáng tạo, năng lực, sở trường, tinh thần và kĩ năng hợp tác của mỗi thành viên trong nhóm. Trong giờ học Tiếng Việt, biện pháp này đã tạo nên một môi trường giao tiếp tự nhiên, thuận lợi, đó là hoạt động giao tiếp nhằm trao đổi, chia sẻ kiến thức, kinh nghiệm của những người bạn.

\section{Tổ chức dạy học ngoài không gian lớp học}

Trong dạy học truyền thống, dạy học ngoài không gian lớp học hay lóp học mở được hiểu rất rộng bao gồm các cuộc dã ngoại, các hoạt động ngoại khóa, các câu lạc bộ, các cuộc thi thử tài... Sau đây chúng tôi chỉ bàn về hình thức dạy học ngoài trời. 
Dạy học ngoài trời giúp HS tìm hiểu rất nhiều kiến thức, kĩ năng từ cuộc sống. Dạy học ngoài trời là một hình thức tổ chức dạy học có nhiều lợi thế để phát triển năng lực giao tiếp cho HS, một năng lực cần thiết cho tất cả mọi môn học.

Dạy học ngoài trời tạo điều kiện để HS quan sát thiên nhiên, chơi các trò chơi... để gây hứng thú, sự tích cực học tập cho các em. Tổ chức tiết học ngoài trời sẽ giúp HS tri giác trực tiếp đối tượng và ghi nhớ tốt, không phải tri giác gián tiếp qua các phương tiện dạy học. Các em có điều kiện gần gũi, hiểu biết về thiên nhiên, từ đó có ý thức bảo vệ thiên nhiên và môi trường sống xung quanh. Hoạt động ngoài lớp còn là cơ hội để các em bộc lộ cá tính, năng khiếu, sở trường, đồng thời có tác dụng hình thành thói quen hợp tác, tương trợ, học hỏi lẫn nhau. Ngoài ra, trong môn Tiếng Việt, nhiều nội dung nói viết của phân môn tập làm văn gắn liền với môi trường địa phương, nơi HS đang sinh sống nên việc dạy học ngoài không gian lớp học lại càng quan trọng.

Có thể nói, bình diện phương pháp và hình thức tổ chức dạy học là bình diện mang tính linh hoạt mềm dẻo, đa dạng nhất trong quá trình dạy học, tác động vào nó có nhiều lợi thế nhất để tạo hứng thú học tập cho HS mà dăm ba trang viết không có tham vọng trình bày được đầy đủ. Sau đây, chúng tôi chỉ đi vào minh họa bằng một vài biện pháp tạo hứng thú học toán cho HS tiểu học trên bình diện này.

Theo quan niệm của GS Nguyễn Bá Kim (trang 102 [1]): Phương pháp dạy học được hiểu là “cách thức hoạt động và giao lưu của thày gây nên những hoạt động và giao lưu cần thiết của trò nhằm đạt được mục đích dạy học" Theo quan niệm này, phương pháp dạy học được xem là phương tiện tư tưởng nhằm đạt mục đích dạy học; Phương pháp dạy học được hiểu theo nghĩa rộng và có tính khái quát nhưng vẫn được xác định khá chặt chẽ bởi mục đích sư phạm với các nội dụng dạy học cụ thể. Mọi thuyết minh về sử dụng phương pháp khéo léo tài tình đều trở nên vô nghĩa nếu người học không có kết quả (không hiểu biết thêm kiến thức và không đạt được kỹ năng tương ứng). Ngay cả khi đạt được kết quả thì các kết quả đó có thực chất và bền vững hay không phụ thuộc rất lớn (nếu không nói là hoàn toàn) vào mức độ hứng thú của người học. Vậy thực chất của việc tạo hứng thú học toán cho HS trên bình diện phương pháp và hình thức tổ chức dạy học là tạo ra được các tình huống để HS tiếp cận, vận dụng nội dung toán học thiết thực và tự nhiên. Sự hình thành mỗi kiến thức toán học như sự phát triển tất yếu của hệ thống các nhu cầu nhận thức của họ. Khi các nhu cầu nhận thức được thỏa mãn thì đó chính là bản chất bên trong của hứng thú chứ không phải là các khẩu hiệu hoặc biểu tượng bề ngoài. Phương pháp dạy học thể hiện vai trò là phương tiện tư tưởng ở chỗ tạo được điểm tựa để HS tự trải nghiệm; tự điều chỉnh các kiến thức và kỹ năng sẵn có để tiếp nhận tri thức mới vào hệ thống tri thức của cá nhân. Yêu cầu này chỉ được hiện thực hóa thông qua việc thiết kế công phu từng họat động thành phần cho mỗi nội dung học tập của HS. Một số ví dụ dưới đây, xem như những minh họa bước đầu cho biện pháp kích thích từ bên trong của quá trình nhận thức nhằm tạo hứng thú học toán cho $\mathrm{HS}$ tiểu học. 


\section{Thiết kế các trò chơ học tập để HS tiếp cận kiến thức toán môt cách nhẹ nhàng, thư vị}

Ví dụ 1: Với mục tiêu là: Hình thành biểu tượng (khái niệm ban đầu) về diện tích một hình (Toán 3 - trang 150); chúng ta hãy thử nghiệm hai cách thiết kế dưới đây để cảm nhận về sự khác biệt tâm lý và thái độ học tập của HS:

\section{Cách 1: Nghe giảng và xem minh họa}

GV có một hình tròn (miếng bìa đỏ hình tròn), một hình chữ nhật (miếng bìa trắng hình chữ nhật). Đặt hình chữ nhật nằm trọn trong hình tròn. Ta nói: Diện tích hình chữ nhật bé hơn diện tích hình tròn. (GV chỉ vào phần mặt miếng bìa màu trắng bé hơn phần mặt miếng bìa màu đỏ) (Sách Giáo viên Toán 3, trang 235).

\section{Cách 2: Vui chơi có thưởng}

GV chia nhóm 4 HS; mỗi nhóm nhận một tờ giấy kẻ 100 ô vuông (10 x 10) và hai bút dạ khác màu (xanh - đỏ); Hai nhóm ngồi đối diện.

Chơi Oản-tù-tì; nhóm nào thắng thì được tô vào 4 ô (yêu cầu tô lần lượt từng hàng) sau hai phút dừng lại kiểm tra. Nhóm tô được phần giấy rộng hơn thì thắng cuộc. Các nhóm thắng cuộc thì dán kết quả tô lên bảng lớp.

GV yêu cầu so sánh mức độ rộng - hẹp của phần giấy đã tô mà các nhóm được dán trên bảng, (nêu cách nhận biết). Trao thưởng cho nhóm đã tô được phần giấy rộng nhất.

GV chỉ vào phần giấy của nhóm đã tô rộng nhất và giới thiệu: ta nói nhóm này tô được diện tích lớn nhất.

Cách 1: HS phải nghiêm túc chăm chú quan sát hình vẽ; và lắng nghe lời giải thích của GV; để nhận biết một cách trực giác là: hình này nằm trọn trong hình kia thì diện tích hình này bé hơn diện tích hình kia. Từ đó có biểu tượng ban đầu về diện tích một hình.

Cách 2: HS nhận đồ dùng (bút màu và giấy kẻ ô); cùng nhau oản tù tì để chơi và tạo ra phần giấy được tô màu (theo các hàng, cột); so sánh lần 1 , HS nhận ra trong 2 nhóm, nhóm nào tô rộng hơn thì được dán lên bảng. So sánh lần 2 , HS nhận ra nhóm tô được phần giấy rộng nhất trong các nhóm đã dán lên bảng. Khi giải thích kết quả so sánh HS có thể quan sát; có thể đặt chống lên nhau; có thể đếm số ô vuông đã tô màu. Như vậy, HS nhận biết: diện tích hình này bé hơn diện tích hình kia (không chỉ bằng trực giác hình này nằm trọn trong hình kia). Các hoạt động được thiết kế đã giúp HS tự kiến tạo và tiếp cận biểu tượng ban đầu về diện tích một hình khá nhẹ nhàng, lý thú.

Ví dụ 2: Với mục tiêu: Thành lập bảng đơn vị đo độ dài và nhận biết quan hệ giữa hai đơn vị đo liền kề. (bài: Bảng đơn vị đo độ dài; SGK Toán 3 trang 45), chúng ta cũng thử nghiệm 2 cách thiết kể hoạt động học tập của HS dưới đây: 


\begin{tabular}{|c|c|}
\hline $\begin{array}{l}\text { Cách 1: Hướng dẫn cách lập bảng và } \\
\text { nêu lên quan hệ }\end{array}$ & $\begin{array}{l}\text { Cách 2: Vui chơi có thưởng để tự hình thành } \\
\text { bảng và nêu quan hệ }\end{array}$ \\
\hline $\begin{array}{l}\text { "GV yêu cầu nêu các đơn vị đo độ dài đã } \\
\text { học. HS có thể nêu không theo thứ tự nhất } \\
\text { định, GV hướng dẫn HS điền dần vào bảng } \\
\text { kẻ sẵn để cuối cùng có một bảng hoàn thiện } \\
\text { như trong SGK. Chẳng hạn: Khi HS lần lượt } \\
\text { nêu các đơn vị đo độ dài, GV có thể viêt ra } \\
\text { ở phần bảng khác (theo thứ tự HS nêu). Khi } \\
\text { HS đã nêu đủ } 7 \text { đơn vị đo độ dài thì GV cho } \\
\text { HS nêu đơn vị đo cơ bản là mét; GV ghi chữ } \\
\text { "mét" vào cột giữa của bảng kẻ sẵ; ghi ký } \\
\text { hiệu "m" ở dòng dưới cùng cột. Sau đó GV } \\
\text { cho HS nhận xét có những đơn vị đo nhỏ } \\
\text { hơn mét ta ghi ở các cột bên phải cột mét, } \\
\text { GV ghi chữ "nhỏ hơn mét" vào bảng kẻ } \\
\text { sẵn. Có các đơn vị đo lớn hơn mét ta ghi các } \\
\text { đơn vị lớn hơn mét ở bên trái cột mét, GV } \\
\text { ghi chữ "lớn hơn mét" vào bảng kẻ sẵn.... } \\
\text { GV cho HS nhìn bảng và lần lượt nêu quan } \\
\text { hệ giữa hai đơn vị đo liền nhau... } \\
\text { GV cho HS đọc nhiều lần để ghi nhớ bảng. } \\
\text { (SGV Toán } 3 \text { trang } 86 \text { ) }\end{array}$ & 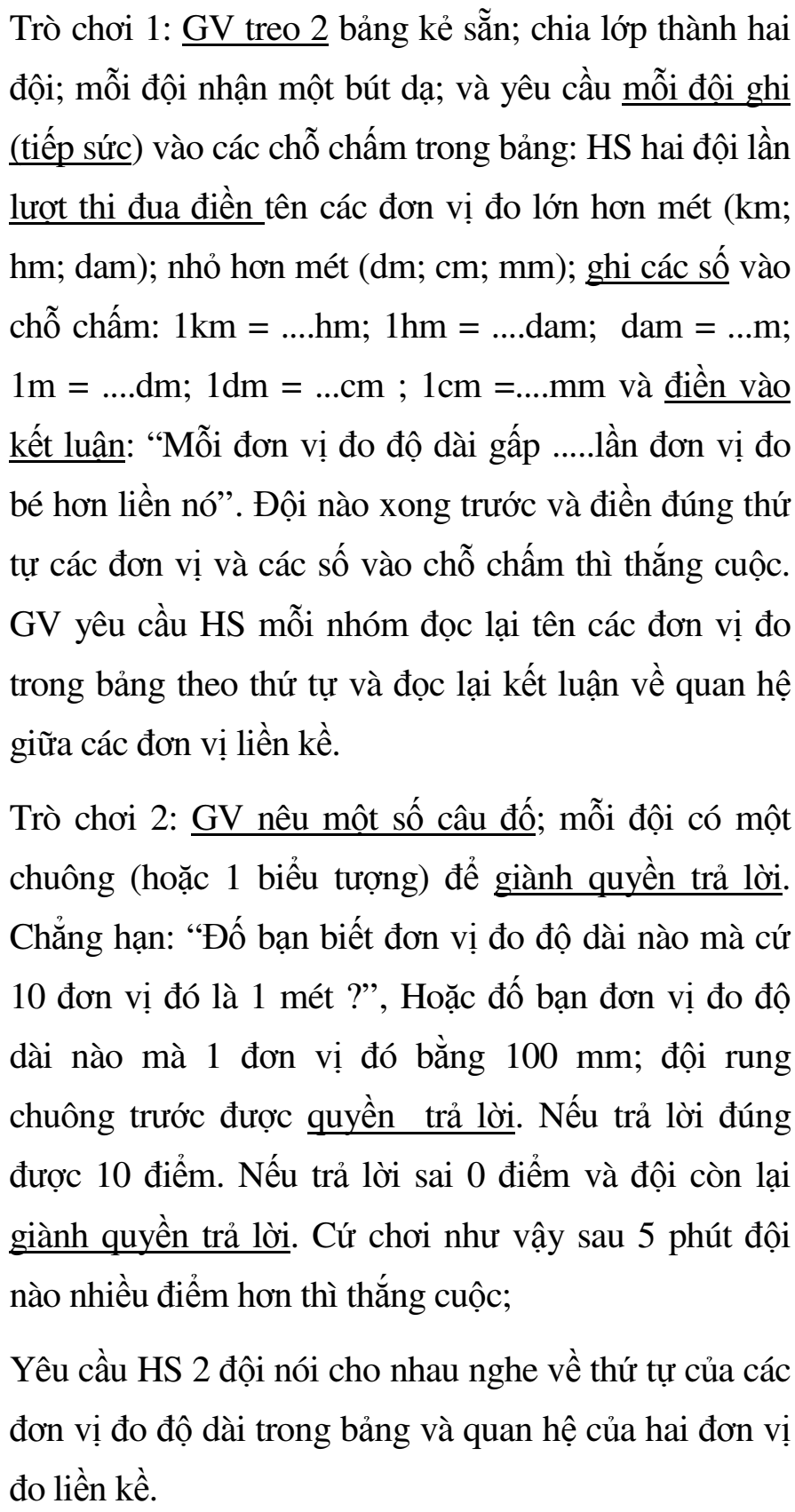 \\
\hline
\end{tabular}

Cách 1: Thể hiện rõ vai trò của GV qua các hoạt động (được gạch chân) trong quá trình hoàn

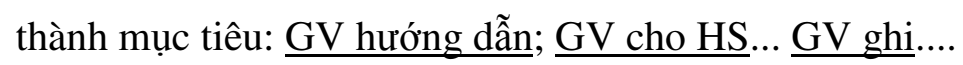

Cách 2: Thể hiện rõ vai trò của HS tự huy động kiến thức vốn có; tự thể hiện kỹ năng; tự phát hiện quan hệ qua các hoạt động (được gạch chân) trong quá trình hoàn thành mục tiêu: mỗi đội ghi (tiếp sức); thi đua điền số; điền vào kết luận; giành quyền trả lời...

Thiết kế các hoạt động thục hành đa dạng gắn với việc giải quyết nhu cầu thiết thục trong đời sống để HS nhận biết giá trị của tri thức toán học 
Ví dụ 1: Bài Thực hành xem lịch (SGV Toán 2, trang 140)

\begin{tabular}{|l|l|}
\hline \multicolumn{1}{|c|}{ Kiến thức và kỹ năng của bài học } & Hoạt động thực hành gắn với nhu cầu thiết thực \\
\hline $\begin{array}{l}\text { - Rèn kỹ năng xem lịch tháng (nhận biết thứ, } \\
\text { ngày, tháng trên lịch) }\end{array}$ & $\begin{array}{l}\text { - Hỏi các thành viên trong gia đình em (bố, mẹ, } \\
\text { anh, chị hoặc em) để biết ngày sinh nhật của } \\
\text { từng người. }\end{array}$ \\
$\begin{array}{l}\text { ngày, tháng, tuần lễ, biểu tượng thời gian (phân } \\
\text { biệt thời điểm với khoảng thời gian) }\end{array}$ & $\begin{array}{l}\text { - Xem lịch rồi khoanh lại (hoặc ghi ra vở) các } \\
\text { ngày sinh nhật của mồi người trong gia đình } \\
\text { em năm nay; nhớ ghi rõ ngày đó là thứ mấy } \\
\text { trong tuần. } \\
\text { Chẳng hạn: Sinh nhật của bố em là: } \\
\text { Ngày.....tháng.....và là thứ.......trong tuần }\end{array}$ \\
\hline
\end{tabular}

Khi yêu cầu HS điền các ngày còn trống của một tờ lịch tháng nào đó; hoặc liệt kê các ngày thứ... trong tuần nào đó của 1 tháng, hoặc khoanh vào một ngày nào đó trên tờ lịch... đều là hoạt động thực hành đúng với mục tiêu bài học nhưng khô khan và thuần túy kiến thức.

Khi thiết kế hoạt động thực hành gắn với các nhu cầu cuộc sống như trên chúng ta đã gợi lên những cảm xúc cho người học khi thực hành từ những việc làm tương tự.

Ví dụ 2: Thực hành nhận dạng các hình. Sau khi HS lớp hai học bài: Hình chữ nhật hình tứ giác; Thay cho việc yêu cầu HS quan sát và đếm hình trong 1 hình vẽ đã cho, có thể thiết kế hoạt động thực hành như sau: a) Chọn các hình thích hợp trong bộ đồ dùng học toán để xếp thành các hình dưới đây: b) Nói cho bạn nghe hình vừa xếp được tạo dáng của vật nào thường thấy hàng ngày.
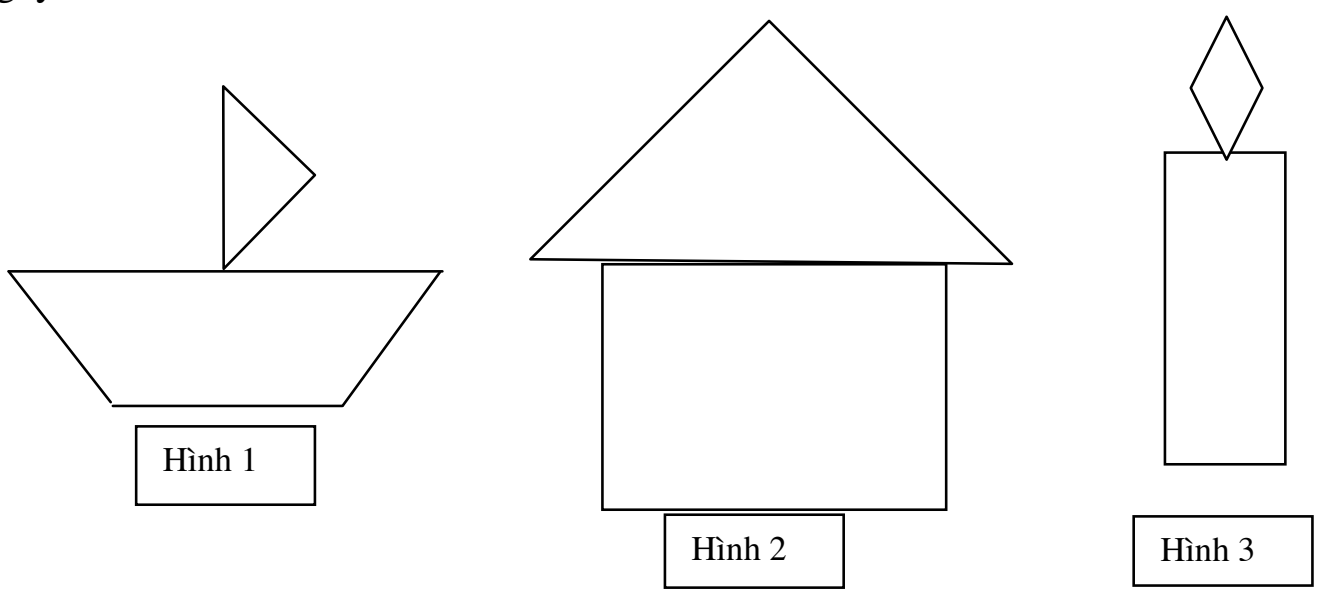

Tóm lại, việc thiết kế các hoạt động học tập giúp HS hứng thú học toán là sự thể hiện tổng hợp các ý tưởng về phương pháp dạy học. Người thiết kế không chỉ xác định đúng đắn mục tiêu học tập, mà còn phải chú ý các yếu tố về tâm lý học, về giáo dục học và hiểu rõ vốn kiến thức thực tiễn của HS để phối hợp tốt với các thủ thuật, kỹ thuật thể hiện nội dung toán học, tạo ra các kích thích hợp lý để HS tự học. 


\section{Tạo hứng thú học tập bằng việc xây dụng môi trường thân thiện giữa thầy và trò, trò và trò}

Bên cạnh việc tác động vào nội dung và phương pháp, hình thức tổ chức dạy học, việc thiết lập được mối quan hệ hợp tác tích cực tốt đẹp giữa thầy và trò, giữa các trò cũng sẽ tạo hứng thú cho HS. Hình thức tổ chức dạy học hấp dẫn cùng với một bầu không khí thân ái hữu nghị trong giờ học sẽ tạo ra sự hứng thú cho cả thầy và trò. Bởi vì, học là hạnh phúc không chỉ vì những lợi ích mà nó mang lại, mà hạnh phúc còn nằm ngay trong chính sự học. Cần hiểu điều này như hiểu câu nói của Mác: "Hạnh phúc là đấu tranh" không chỉ bởi những thành quả đấu tranh mang lại mà còn bởi chính trong đấu tranh có hạnh phúc. Chính vì vậy, bên cạnh việc giáo dục tính mục đích, tính kỉ luật, ý thức về trách nhiệm v.v... cho HS, chúng ta phải tổ chức cuộc sống ở trường thật hấp dẫn, tạo niềm vui, phải phấn đấu sao cho "mỗi ngày các em đến trường là một ngày vui". Mỗi HS mong muốn và phải là người được hạnh phúc ngay ngày hôm nay, còn chúng ta sẽ là người kém cỏi nếu mỗi giây phút tiếp xúc với chúng ta, các em không được vui sướng, hạnh phúc. Bởi vậy, chúng ta phải thường xuyên tìm hiểu HS muốn việc học diễn ra như thế nào, cái gì làm các em thích, cái gì làm các em không thích để có thể tổ chức quá trình dạy học như các em mong đợi. Để tạo hứng thú cho HS, người GV Tiểu học cần biết tổ chức quá trình dạy học theo một chiến lược lạc quan: Chú trọng vào mặt thành công của trẻ. Chúng ta cần tập cho mình có một cách nhìn: HS tiểu học em nào cũng ngoan, em nào cũng giỏi, em nào cũng cố gắng. Chỉ có em này ngoan, giỏi, cố gắng nhiều hơn, em kia ngoan, giỏi, cố gắng ít hơn mà thôi. GV Tiểu học phải có một phẩm chất đặc biệt, biết cách cư xử đặc biệt với HS. Đó là thái độ nâng đỡ, khích lệ, thông cảm, chú trọng vào mặt thành công của các em. Đó là khả năng biết tự kiềm chế, khả năng đồng cảm với HS, khả năng làm việc kiên trì tỉ mỉ. Đó là khả năng biết tổ chức quá trình dạy học một cách nhẹ nhàng tự nhiên không gây căng thẳng cho HS. Chúng ta phải có sự hiểu biết về HS, hình dung thấy hết những khó khăn mà các em gặp phải trong học tập để bình tĩnh trước những sai sót của các em và có biện pháp phòng ngừa. Chú trọng vào mặt thành công, chúng ta phải đề cao tính sáng tạo của HS. Cần phải biết tỏ ra ngạc nhiên, vui sướng, cần phải tôn trọng những sáng tạo của HS, dù rất nhỏ. Đừng tỏ ra rằng thầy luôn luôn đúng, chỉ có thầy là người nắm chân lí. Thầy giáo cũng cần làm cho HS hiểu rằng thầy cũng có thể sai lầm và cần được các em giúp đỡ. Lúc này lỗi của thầy sẽ kéo theo sự chuyển động tư duy của HS. Các em sẽ sung sướng vì được làm người đầu tiên tìm ra chân lí. Việc chú trọng vào mặt thành công của trẻ đòi hỏi chúng ta phải xây dựng các nhiệm vụ dạy học sao cho bảo đảm để các em có những thành công chắc chắn đầu tiên chứ không phải là những thất bại cay đắng đầu tiên.

\section{Tạo hứng thú học tập bằng việc đổi mới quan niệm và cách thức kiểm tra, đánh giá}

Điều cuối cùng chúng ta cần chú ý là cách kiểm tra đánh giá . Có rất nhiều chuyện để bàn và để làm trong việc đổi mới đánh giá, kiểm tra trong hệ thống dạy học của chúng ta. Bài viết này của chúng tôi chỉ muốn nhấn mạnh và khuyến cáo một lần nữa rằng: Phải đánh giá, kiểm tra kết quả học tập của HS tiểu học theo một chiến lược dạy học lạc quan - đó là nhấn mạnh vào mặt thành công của HS.

Việc đòi hỏi dạy học phải nghiêm khắc và đặt ra yêu cầu cao với HS không có nghĩa là cho phép chúng ta khắt khe trong đánh giá và chặt chẽ khi cho điểm. Một trong những nguyên nhân 
khiến HS không thích học là do cách đánh giá bằng lời và cho điểm của chúng ta không thỏa đáng. Đọc, viết như thế nào, GV cũng có thể tìm ra chỗ "có thể chê được". Còn về điểm số thì có cô giáo cho rằng đọc, tập viết hay viết bài tập làm văn được điểm 8 là tốt quá rồi (!). Chúng ta cần phải tự đặt ra câu hỏi "ta có thể đặt ra yêu cầu gì với HS tiểu học để đánh giá, cho điểm hợp lí đặng khuyến khích, kích thích HS học tốt hơn?”. Đạt được thành công trong học tập sẽ tạo ra hứng thú và niềm say mê học tập của HS. Chỉ có thành công (chứ không phải là những thất bại cay đắng), niềm tự hào về thành công, cảm giác xúc động khi thành công mới là nguồn gốc thật sự của ham muốn học hỏi.

\section{TÀI LIỆU THAM KHẢO}

1. Nguyễn Bá Kim (2002), Phương pháp dạy học môn Toán, Nxb Đại học Sư phạm.

2. Nguyễn Hữu Châu - chủ biên (2004), Phuơng pháp, phuoong tiện, kĩ thuật và hình thức tổ chức dạy học trong nhà trường, Nxb Đại học Sư phạm.

3. Đỗ Đình Hoan - chủ biên, Sách giáo khoa Toán 2; 3; 4.

4. Đỗ Đình Hoan - chủ biên, Sách giáo viên Toán 2; 3; 4.

5. Wilbert J. McKeachic, Nhũng thủ thuật trong dạy học; tái bản lần thứ $2 / 2003$. Bản quyền của College Permissions Houghton Miflin company.

6. Trần Ngọc Lan, "Một số thủ thuật thường dùng để đề xuất các bài toán cho học sinh tiểu học"; Tạp chí Giáo dục, số 31, 2/2002.

7. Trần Ngọc Lan, "Sử dụng kĩ thuật đặt câu hỏi trong dạy học Toán ở tiểu học nhằm tích cực hóa hoạt động học tập của học sinh", Tạp chí Giáo dục, số145, 9/2006.

8. Vũ Thị Lan (2008), "Các biện pháp tạo hứng thú học tập cho học sinh nhằm nâng cao hiệu quả dạy học Tiếng Việt ở tiểu học", Luận án tiến sĩ.

9. Nguyễn Thị Thanh Nhài - Lê Phương Nga, "Một số biện pháp tạo hứng thú cho học sinh lớp 1 để nâng cao hiệu quả học tập trong giờ học Tiếng Việt", Tập san Giáo duc Tiểu học, Số $2 / 2012$.

10. Lê Phương Nga, "Bảo đảm sự thành công của học sinh trong giờ học Tiếng Việt những ngày đầu đến trường”; Tạp chí Tâm lí học, Số 2/2004. 